\title{
Income Inequality and Risk of Suicide in New York City Neighborhoods: A Multilevel Case-Control Study
}

\author{
Jeffrey R. Miller, MPH, Tinka Markham Piper, MPH, Jennifer Ahern, MPi, \\ Melissa Tracy, MPH, Kenneth J. Tardiff, MD, MPH, David Vlahov, PhD, \\ and Sandro Galea, $\mathrm{MD}, \mathrm{D}_{\mathrm{R}} \mathrm{PH}$
}

Evidence on the relationship between income inequality and suicide is inconsistent. Data from the New York City Office of the Chief Medical Examiner for all fatal injuries was collected to conduct a multilevel case-control study. In multilevel models, suicide decedents $(n=374)$ were more likely than accident controls $(n=453)$ to reside in neighborhoods with greater income inequality even after controlling for individual characteristics; this relation was modified by age with an effect overall and among decedents aged 15-34 but not among decedents $35-64$. These data suggest that income inequality may contribute to the risk of suicide in younger adults.

A combination of genetic, psychological, and psychosocial factors likely contribute to the risk of suicide (Berkman, Glass, Brissette, \& Seeman, 2000; Cullen \& Whiteford, 2001; Kawachi \& Berkman, 2001; Mann et al., 2000; Stanley \& Mann, 1983; Stanley, Virgilio, \& Gershon, 1982). Psychosocial factors (e.g., social support, social strain) are impor-

From the Center for Urban Epidemiologic Studies, New York Academy of Medicine (JefFrey Miluler, Tinka Markham Piper, Jennifer Ahern, Melissa Tracy, David Vlahov, and Sandro Galea); Mount Sinai School of Medicine (Mrcler); Department of Psychiatry, Weill Medical College of Cornell University (KenNeTH TARDIFF); and the Department of Epidemiology at Columbia University Mailman School of Public Health (Vlahov and Galea).

This study was funded in part by grants DA-06534 and DA-12801-SI from the National Institute on Drug Abuse.

Address correspondence to Dr. Sandro Galea, Center for Urban Epidemiologic Studies, New York Academy of Medicine, 1216 Fifth Avenue, New York, NY 10029; E-mail: sgalea@nyam.org. tant in determining exposure to life-events, developing coping mechanisms, and shaping behavior that may aggravate or ameliorate an individual's predisposition toward suicide (Berkman et al., 2000; Cullen et al., 2001; Kawachi et al., 2001).

Characteristics of the social environment, such as relative income distribution, also may be important determinants of suicide risk. Sociologists, like Emile Durkheim, have long conceptualized suicide as a social pathology and focused on the importance of social structure in determining population suicide rates (Berkman et al., 2000; Neeleman, 2002). A number of ecological studies have shown that characteristics of the social context, including unemployment rates, economic deprivation, and social fragmentation, are associated with population suicide rates (Aihara \& Iki, 2003; Whitley, Gunnell, Dorling, \& Smith, 1999). In contrast to ecological studies of population suicide rates, few studies have considered how contextual factors may shape individual suicide risk and even fewer have done so using multilevel methods 
of analysis (Blakely, Atkinson, \& O'Dea, 2003; Borges, Anthony, \& Garrison, 1995; Borrell et al., 2002; Braucht, 1979; Dooley, Catalano, Rook, \& Serxner, 1989; Neeleman, 2002; Neeleman, Wilson-Jones, \& Wessely, 2001).

Although controversial, the relative distribution of wealth in a society has been hypothesized to affect health in multiple ways. Income inequality may not only be associated with increased economic strain (Akers \& Sellers, 2004) and poorer material conditions for some residents, but also may shape the social context in which people live. Neighborhoods with more inequitably distributed income may have lower collective efficacy (Kawachi, Kennedy, \& Wilkinson, 1999). Other components of social disorganization theory (e.g., urbanization, family disruption, ethnic heterogeneity, residential mobility, and low socioeconomic status) also may be important intermediaries linking income inequality to suicide (Lowenkamp, Cullen, \& Pratt, 2003; Sampson \& Groves, 1989). As a result of these hypothesized pathways, social controls on violence and deviant behavior may be decreased (Kawachi et al., 1999; Kennedy, Kawachi, Prothrow-Stith, Lochner, \& Gupta, 1998; Sampson, Raudenbush, \& Earls, 1997). Income inequality may promote psychosocial strain due to material impoverishment, perceived position in the social hierarchy, decreased sense of control, and a paucity of opportunities (Whitley et al., 1999). In addition, income inequality may lead to maladaptive coping mechanisms including deep discounting of future life chances, greater impulsivity, and more risktaking behavior (Wilson \& Daly, 1997). Therefore it is plausible that income distribution may be an important contextual determinant of suicide risk (Blakely et al., 2003; Fernquist, 2003; Gunnell, Middleton, Whitley, Dorling, \& Frankel, 2003; Lester, 1991; Young \& French, 1996).

There is limited empirical evidence investigating the relation of income inequality to suicide. The results of extant studies are difficult to interpret collectively due to various levels of aggregation and differing study designs involving purely cioss-sectional de- signs, cross-sectional analyses of time-series observations, and measurement of income inequality versus perceived income inequality. Two studies of time-series observations across countries found a higher prevalence of suicide in communities with higher income inequality (Cutright \& Fernquist, 2000) and perceived income inequality (Fernquist, 2003). One study demonstrated an association between greater income inequality and lower suicide rates (Unnithan, 1994). Two studies failed to observe an association between suicide and income inequality (Fernquist \& Cutright, 1998; Lester, 1987). The evidence from studies comparing populations within the same nation are also difficult to interpret. A time-series analysis in England and Wales (Gunnell et al., 2003), and cross-sectional studies of U.S. metropolitan areas (Lynch et al., 1998) and urban counties (Kowalski, Faupel, \& Starr, 1987) found an association between income inequality and suicide. In contrast, no evidence of an association between these factors was found in rural U.S. counties (Kowalski et al., 1987) or Indian Health Service Areas (Young \& French, 1996). Conclusions are also complicated by associations that vary by age and gender in some studies (Cutright et al., 2000; Fernquist, 2003; Gunnell et al., 2003). We are aware of only one multilevel study that looked specifically at income inequality and suicide (Blakely et al., 2003). Blakely et al. found no association between income inequality and individual risk of suicide overall; however, an association between high income inequality and female suicide risk approached statistical significance.

We assessed the potential relation of neighborhood income distribution to individual risk of suicide through a multilevel case-control study of New York City. We hypothesized a priori that living in a neighborhood with greater income inequality is associated with a higher risk of suicide.

\section{METHODS}

We collected data from the New York City (NYC) Office of the Chief Medical Ex- 
aminer (OCME) for all fatal injuries in 1996. The OCME investigates all deaths suspected to have occurred unnaturally within the five boroughs of New York City. The manner of death is determined by the OCME through review of medical records, autopsy, forensic evidence, and investigative interviews. In this case-control analysis, suicides aged 15-64 were cases, and non-overdose accidental deaths aged 15-64 were controls. Accidental deaths included in these analyses as controls were poisoning, asphyxiation, drowning, firearm deaths, stabbing, electrocutions, blunt trauma, crushing, falls, vehicular accidents, burns, explosions, environmental exposures, and other accidents (Galea et al., 2003).

Age, race/ethnicity, and gender, as extracted from the OCME records, were the individual demographics of primary interest in this analysis. Given our intent to analyze the data spatially, decedents were excluded if there was incomplete documentation of their residential address. Each decedent was assigned to his/her community district of residence, allowing community districts to serve as our area of aggregation. The 59 community districts in New York City were established in 1975 in an attempt to define segments of the city that are relatively homogenous in terms of land use and population (Wallin, Schill, \& Daniels, 2002). There is significant diversity between community districts (Wallin et al., 2003) and they are thought to reflect natural neighborhood divisions. Each community district is a separate political entity represented by a community board (Wallin et al., 2002, 2003). Precedence exists for using community districts in public health and population studies; the NYC Department of Health and Department of City Planning regularly report health and demographic data at the level of the community district. Other epidemiologic studies have also been conducted using community districts as the area of aggregation (Finkel \& Elkin, 2001; Galea et al., 2003; Marzuk et al., 1997; Messner \& Tardiff, 1986).

Contextual variables of interest included a measure of mean neighborhood income and two measures of income inequality. We calculated the mean income of each community district using 1990 U.S. Census per capita income data (Bureau of the Census, 1999). We operationalized income inequality in two ways: as the Gini coefficient (Galea et al., 2003; Kawachi \& Kennedy, 1997) and as the percent of total income earned by the lowest earning $70 \%$ of households within each community district (Galea et al., 2003; Kawachi et al., 1997). These measures of income inequality were calculated from 1990 U.S. Census Data (Bureau of the Census, 1999) using household measures of income. Analyses using both methods of calculating income inequality resulted in identical conclusions and as such we present here only data and analyses regarding the Gini coefficient. Data and analyses about the percent of total income earned by the lowest earning $70 \%$ of households is available from the authors.

We used chi-square tests and $t$ tests to look for differences in the demographic characteristics of suicide and accident decedents. We fit bivariate logistic regression models to initially examine the associations of demographic characteristics, neighborhood income, and income inequality with manner of death. We modeled neighborhood per capita income with a quadratic term since this may theoretically and empirically be a better representation of the role of income in explaining population health (Deaton, 2003; Judge \& Paterson, 2001).

We plotted the ecological association between both measures of income inequality and suicide rate per 100,000 person-years. We fit multivariate, multilevel logistic regression models using generalized estimating equations to explore the hypothesized relations between suicide, individual characteristics of each decedent (race and age), income distribution, and mean neighborhood per capita income (Zeger \& Liang, 1986). We further analyzed the resulting models by stratifying the decedents into two groups at the approximate midpoint of the sample's age distribution. We estimated the degree to which income inequality was associated with an increased individual risk of death by suicide relative to having a fatal accident by cal- 
culating odds ratios for the range of income inequality observed across community districts in our study using the midpoint of the most egalitarian decile as the referent.

\section{RESULTS}

Decedents were excluded if they could not be assigned to a NYC community district based on their residence. Most $(n=70)$ of the dropped individuals were not residents of NYC; 14 were known to be homeless; 11 could be assigned to a borough but not to a community district and the rest $(n=56)$ had no available address information. Forty-nine cases (11.6\% of suicides) and 102 controls (18.4\% of accidents) were excluded resulting in 374 suicide cases and 453 accident controls. The demographics of individuals without a known residence were similar to those individuals with a known residence. Overall and among accident controls, excluded individuals were slightly younger than included individuals (mean age overall $=37.4$ vs 39.9 , $\mathrm{p}=0.033$; mean age of controls $=37.5$ vs $40.6, p=0.034)$. There were no significant differences between included and excluded suicide cases and there were also no other significant differences between included and excluded accident controls.

Table 1 describes the demographic characteristics of the decedents in our sample. Four hundred and twenty-three persons committed suicide and 555 persons had a non-overdose fatal accident in the five boroughs of New York City during 1996 (total $n=978$ ). The mean ages of cases and controls were $38.9(S D=12.6)$ and $40.6(S D=$ 13.47) respectively. The difference in mean age of cases and controls approached statistical significance $(p=0.06)$. Cases and controls did not vary by gender, but cases were more likely than controls to be White.

Table 1 also describes the community districts in the sample. The average Gini coefficient among suicide and accident decedents were $0.45(S D=0.03)$ and $0.44(S D=$ 0.04 ), respectively. The neighborhood per capita income among suicide decedents was
$\$ 17,809.92(S D=\$ 12717.19)$; the neighborhood per capita income among accident decedents was $\$ 14,550.02(S D=\$ 9004.96)(p<$ $0.001)$.

Table 2 presents bivariate logistic regression models of the associations between potential individual- and neighborhood-level determinants and the likelihood of death occurring as a result of committing suicide versus having a fatal accident. Cases (suicide decedents) were more likely than controls to be White, but less likely to be Black or Hispanic. Increasing age was associated with a decreased likelihood of death occurring as a result of suicide, though this association was not statistically significant. No differences were seen between cases and controls by race/ ethnicity, measure of income inequality, per capita income, or per capita income squared.

Figure 1 depicts the ecological associations between measures of income inequality and the rates of suicide death by community district. The associations were best represented using a spline model. Both measures of income inequality were associated with higher rates of suicide death. The degree of income inequality was represented positively by the Gini coefficient, whereas the degree of income inequality was inversely represented by the percent of income earned by the lowest earning $70 \%$ of households.

Table 3 presents three multilevel multivariable models. The models control for covariates allowing further exploration of associations between potential individual- and neighborhood-level determinants and the likelihood of death occurring as a result of committing suicide versus having a fatal accident. The last two models stratify the data by age.

Among decedents aged 15 to 64, suicide decedents (cases) were more likely than fatal accident victims (controls) to be younger $(p=0.013)$ and to live in neighborhoods with high income inequality $(p=$ $0.019)$, but less likely to be Black $(p<0.001)$ or Hispanic $(p<0.001)$; no differences in cases and controls were seen by gender, per capita income, or the quadratic form of per capita income. 
TABLE 1

Demographic and Neighborhood Characteristics of Suicide and Accident Deaths (Age 15-64); New York City, 1996

\begin{tabular}{|c|c|c|c|c|c|}
\hline \multirow{2}{*}{$\begin{array}{l}\text { Individual } \\
\text { characteristics }\end{array}$} & \multicolumn{2}{|c|}{$\begin{array}{l}\text { Suicide Deaths } \\
\qquad(\mathrm{n}=374)\end{array}$} & \multicolumn{2}{|c|}{$\begin{array}{l}\text { Accident Deaths } \\
\quad(\mathrm{n}=453)\end{array}$} & \multirow[b]{2}{*}{ p value* } \\
\hline & M & SD & M & SD & \\
\hline \multirow[t]{2}{*}{ Age } & 38.93 & 12.60 & 40.63 & 13.47 & 0.06 \\
\hline & $N$ & $\%$ & $N$ & $\%$ & $\mathrm{p}$ value* \\
\hline \multicolumn{6}{|l|}{ Gender } \\
\hline Male & 289 & 77.30 & 357 & 78.80 & 0.60 \\
\hline Female & 85 & 22.70 & 96 & 21.20 & \\
\hline \multicolumn{6}{|l|}{ Race/Ethnicity } \\
\hline White & 183 & 48.90 & 135 & 29.80 & $<0.001$ \\
\hline Black & 69 & 18.50 & 152 & 33.50 & \\
\hline Hispanic & 87 & 23.30 & 129 & 28.50 & \\
\hline Other & 35 & 9.40 & 37 & 8.20 & \\
\hline $\begin{array}{l}\text { Neighborhood } \\
\text { characteristics }\end{array}$ & M & SD & M & SD & $p$ value* \\
\hline Gini coefficient† & 0.45 & 0.03 & 0.44 & 0.04 & 0.14 \\
\hline Per capita income ${ }^{\star *}$ & $\$ 17,809.92$ & $\$ 12,717.19$ & $\$ 14,550.02$ & $\$ 9,004.96$ & $<0.001$ \\
\hline $\begin{array}{r}{ }^{*} \text { Chi-square te } \\
{ }^{* *} \text { Mean neigh } \\
+ \text { Measure of } \\
\text { bution) to } 1 \text { (maximal }\end{array}$ & $\begin{array}{l}\text { st for categor } \\
\text { orhood incon } \\
\text { come distribu } \\
\text { maldistribution }\end{array}$ & $\begin{array}{l}\text { cal variables a } \\
\text { te from } 1990 \\
\text { tion; ranges } \mathrm{f}\end{array}$ & $\begin{array}{l}\text { nd } t \text { test for } \mathrm{c} \\
\text { US Census D } \\
\text { om } 0 \text { (perfectl) }\end{array}$ & $\begin{array}{l}\text { ntinuous va } \\
\text { ta } \\
\text { equitable ino }\end{array}$ & $\begin{array}{l}\text { iables } \\
\text { me distri- }\end{array}$ \\
\hline
\end{tabular}

The findings among decedents aged 15-34 are similar to those of decedents aged 15-64 except with respect to age and per capita income (squared.) Among decedents aged 15-34, suicide decedents (cases) were more likely than fatal accident victims (controls) to live in neighborhoods with high income inequality $(p=0.033)$ and low per capita income (as a quadratic term; $p=0.032$ ), but less likely to be Black ( $p=0.004)$ or Hispanic $(p=0.007)$; no differences were seen between cases and controls by gender or age within this subset of younger decedents.

Among decedents aged 35-64, suicide decedents were more likely than fatal accident victims to be younger $(p=0.007)$ but less likely to be Black $(p<0.001)$ or Hispanic $(p<0.001)$. In contrast to the findings for decedents aged 15-64 and 15-34, no differences were seen between cases and controls by neighborhood income inequality for decedents aged 35-64. There were also no differences between cases and controls by gender, per capita income or the quadratic form of per capita income within this age group.

Figure 2 depicts the predicted odds of death by suicide across the range of Gini coefficients observed in this study, based on our multilevel multivariate logistic regression model. For example, the odds of death due to suicide in neighborhoods with high values of Gini coefficient (greatest income inequality) was 1.9 times the odds of death due to suicide neighborhoods with low values of Gini coefficient (most egalitarian).

\section{CONCLUSIONS}

In this multilevel case-control study in $\mathrm{NYC}$, we found that persons living in neigh- 
TABLE 2

Unadjusted Relations Between Individual and Neighborhood-Level Covariates and Risk of Suicide; New York City, 1996

\begin{tabular}{lrrr}
\hline & Beta & SD & p value \\
\hline $\begin{array}{l}\text { Individual } \\
\text { characteristics }\end{array}$ & & & \\
Age & -0.01 & 0.01 & 0.057 \\
Male** & -0.05 & 0.18 & 0.766 \\
Black $\dagger$ & -1.03 & 0.18 & $<0.001$ \\
Hispanic $\dagger$ & -0.67 & 0.18 & $<0.001$ \\
$\quad$ Other $\dagger$ & -0.37 & 0.26 & 0.153 \\
Neighborhood & & & \\
$\quad$ characteristics & & & \\
$\quad$ Gini coefficient & \\
Per capita income $\neq$ & 2.35 & 2.26 & 0.297 \\
(Per capita income) $^{2} \neq$ & 0.29 & 0.20 & 0.147 \\
\hline
\end{tabular}

* Measure of income distribution; ranges from 0 (perfectly equitable income distribution) to 1 (maximal maldistribution)

${ }^{* *}$ Female referent

tWhite race referent

$\ddagger$ Mean neighborhood income from 1990

U.S. Census Data

borhoods characterized by more inequitable distribution of income had an increased likelihood of committing suicide relative to the likelihood of sustaining a fatal accident. This effect was modified by age. Income inequality was associated with an increased likelihood of death due to suicide among persons under the age of 35 but not among persons 35 years of age or older.

The multilevel design and small-level analysis of neighborhoods within a single city make this study of income inequality and suicide unique. Previously published ecological studies exploring income inequality and suicide have been inconclusive with associations varying by age, gender, level of aggregation, and urbanicity (Cutright \& Fernquist, 2000; Fernquist, 2003; Fernquist \& Cutright, 1998; Gunnell et al., 2003; Kowalski et al., 1987; Lester, 1987; Lynch et al., 1998; Unnithan, 1994; Young \& French, 1996). Our findings are consistent with cross-sectional studies comparing urban populations (Kowalski et al., 1987; Lynch et al., 1998). We are aware of only one other multilevel analysis assessing the potential relation between income inequality and suicide (Blakely et al., 2003). Our findings contradict those of Blakely et al. who, in a multilevel study of 35 areas in New Zealand, found no association between income inequality and individual risk of suicide, though they did find an association that approached statistical significance between high income inequality and female suicide risk. There was no difference between suicide decedents and fatal accident victims by gender in our analysis.

Our findings, consistent with previous cross-sectional studies of urban populations, may suggest that the association between income inequality and suicide is mediated by qualities of the urban environment. Income inequality and the urban environment may interact to increase relative disinvestment, reduce collective efficacy, and increase social strain. Beyond collective efficacy, other components of social disorganization theory, differential opportunities theory, social control theory, social learning theory, social bonding theory, and the classic and contemporary anomie and strain theories of Merton, Cohen, Miller, Messner and Rosenfield, and Agnew (in Akers \& Sellers, 2004) may link income inequality to more proximate biologic, psychologic, and social determinants of suicide.

We found that the association between income inequality and risk of suicide was present only among younger persons. This is consistent with one study that showed that an income inequality-suicide relation existed only for young decedents who did not commit suicide by inhalation or overdose (Gunnell et al., 2003), but is in contrast to findings from an ecologic time-series analysis of data from 1955 to 1989 that found this effect existed only among men 75 and older in all periods and among men ages 55 to 74 after 1960 (Cutright \& Fernquist, 2000).

There are several possible explanations for the mediating effect of age on the association between income inequality and suicide. First, younger persons may have fewer economic resources and greater economic strain (Akers \& Sellers, 2004) and may be more sus- 


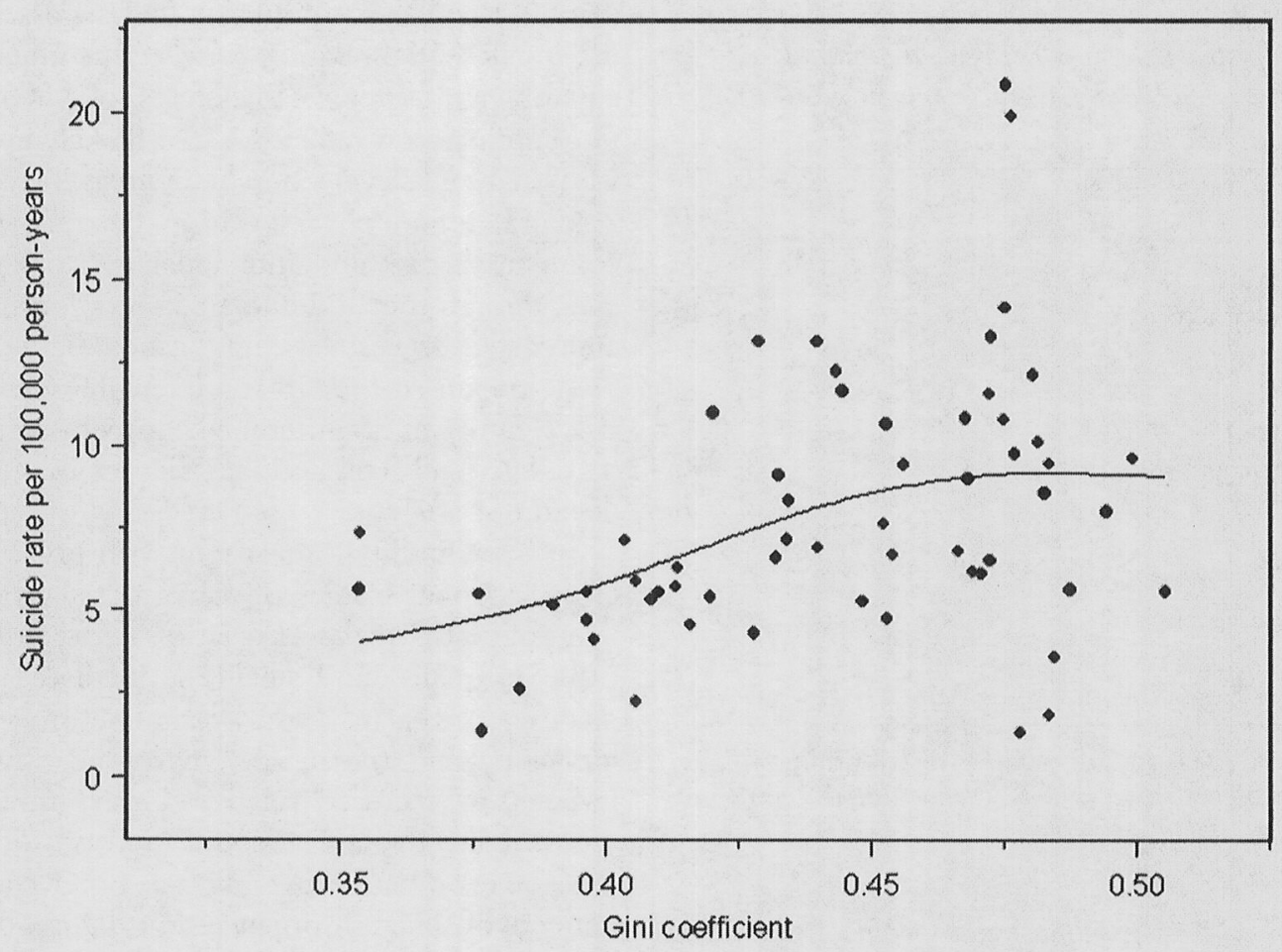

Figure 1. Population suicide rates by Gini coefficient in the neighborhood.

ceptible or may have greater exposure to biological and psychosocial stress. They also may have fewer mitigating resources or benefit less from those resources than older persons. This effect may become more pronounced if younger susceptible persons do not survive to old age in neighborhoods with greater income inequity. Second, income inequality may be related to the incidence of suicide by increasing the number of suicide attempts, but it may also change the incidence of suicide by altering the lethality of each attempt. In a study of attempted and successful suicide in eight states, attempted suicide was more common in younger persons but the rate of completion was higher in older persons (Spicer \& Miller, 2000). This difference was explained by the use of more lethal means of suicide in older persons. Younger persons living in neighborhoods with greater income inequality may be more likely to use more lethal means of suicide in their attempts than younger persons in neighborhoods with less income inequality. For example, young persons in neighborhoods with greater inequity may have greater access to firearms (Berkman et al., 2000; Neeleman, 2002), or they may be more likely to use firearms in their suicide attempts even after controlling for the accessibility of firearms (Kennedy et al., 1998). Third, the relation of income inequality to suicide in younger decedents may reflect neighborhoods with increased social isolation. We calculated neighborhood income inequality using household measures of income. Neighborhoods containing a mixed population of young single-income and older multi-income households may have greater income inequality. Young persons living by themselves without the financial support of another household member may have increased economic strain and may be more susceptible to anomie and the effects of social isolation.

The conclusions that can be drawn from this study are limited by the scope of 


\section{TABLE 3}

Multi-Level Models of the Relation Between Income Inequality Indices and Suicide Mortality for Entire Sample and Stratified by Age; New York City, 1996

\begin{tabular}{|c|c|c|c|}
\hline & \multicolumn{3}{|c|}{ Gini coefficient* } \\
\hline & Beta & $\mathrm{SD}$ & $\mathrm{p}$ value \\
\hline \multicolumn{4}{|l|}{ Ages $15-64$-whole group } \\
\hline Inequality Measure & 5.65 & 2.41 & 0.019 \\
\hline Per capita income $\ddagger$ & 0.11 & 0.19 & 0.587 \\
\hline (Per capita income $)^{2} \ddagger$ & 0.01 & 0.03 & 0.752 \\
\hline Age & -0.02 & 0.01 & 0.013 \\
\hline Male** & -0.02 & 0.17 & 0.921 \\
\hline Black $†$ & -1.11 & 0.21 & $<0.001$ \\
\hline Hispanic† & -0.78 & 0.18 & $<0.001$ \\
\hline Other† & -0.46 & 0.26 & 0.073 \\
\hline \multicolumn{4}{|l|}{ Ages 15-34 } \\
\hline Inequality measure & 6.93 & 3.25 & 0.033 \\
\hline Per capita income $\neq$ & -0.68 & 0.41 & 0.098 \\
\hline$(\text { Per capita income })^{2} \ddagger$ & 0.15 & 0.07 & 0.032 \\
\hline Age & $<0.01$ & 0.02 & 0.843 \\
\hline Male** & -0.21 & 0.26 & 0.412 \\
\hline Black† & -1.10 & 0.39 & 0.004 \\
\hline Hispanic $†$ & -0.85 & 0.32 & 0.007 \\
\hline Other† & -0.50 & 0.36 & 0.164 \\
\hline \multicolumn{4}{|l|}{ Ages $35-64$} \\
\hline Inequality measure & 4.16 & 3.12 & 0.182 \\
\hline Per capita income $\neq$ & 0.49 & 0.31 & 0.118 \\
\hline$(\text { Per capita income })^{2} \ddagger$ & -0.05 & 0.05 & 0.276 \\
\hline Age & -0.03 & 0.01 & 0.007 \\
\hline Male** & 0.12 & 0.25 & 0.623 \\
\hline Black $†$ & -1.08 & 0.25 & $<0.001$ \\
\hline Hispanic $†$ & -0.69 & 0.20 & $<0.001$ \\
\hline Other $†$ & -0.36 & 0.36 & 0.316 \\
\hline
\end{tabular}

${ }^{*}$ Measure of income distribution; ranges from 0 (perfectly equitable income distribution) to 1 (maximal maldistribution)

${ }^{* *}$ Female referent

+White race referent

$\ddagger$ Mean neighborhood income from 1990 U.S. Census Data

our data collection. Mortality data does not reflect unsuccessful suicide attempts or suicidal ideation. The relation between income inequality and attempted suicide may be different from the relation of income inequality to the risk of completed suicide. Other limitations of our study include the potential misclassification of suicides and non-over- dose fatal accidents. Official records may underestimate the prevalence of suicide by as much as $10-38 \%$ (Carr, Hoge, Gardner, \& Potter, 2004; Ohberg \& Lonnqvist, 1998; Ovenstone, 1973). The validity of suicide prevalence rates has been questioned in studies of suicide trends and cross-population comparisons (Brent, Perper, \& Allman, 1987; Lester, 1992; Mohler \& Earls, 2001). Suicides may be misclassified as undetermined deaths or fatal accidents particularly if the decedent died from violent means or an overdose (Brent et al., 1987; Ohberg \& Lonnqvist, 1998). Misclassification of suicide may occur more often for decedents who are young, Black (Mohler et al., 2001), or male (Ohberg et al., 1998); however, these findings are not consistent across studies (Brent et al., 1987). The NYC OCME uses multiple investigative means to obtain unbiased determinations of the manner of death. While misclassification may still occur, the data used in this study is from a single medical examiner's office from 1996, maximizing the validity of cross-population comparisons and minimizing any potential changes in misclassification over time. Although the exclusion of fatal accidents resulting from an overdose does nothing to correct case ascertainment, it probably decreases the probability of confusing a case as a control (Ohberg \& Lonnqvist, 1998). Despite these precautions, it is possible that our findings are confounded by the misclassification of suicide and non-overdose fatal accidents if there are differences in case ascertainment by age, level of income inequality, or neighborhood of residence.

Our decision to use community districts as our level of aggregation is supported by its representation of a political unit with relative intra-neighborhood homogeneity and inter-neighborhood diversity. Furthermore, in the case of suicide, it is at this level that some effects of collective efficacy and other neighborhood determinants might be mediated. The extant literature seems to suggest a more consistent effect of income inequality on suicide in urban environments, especially relative to population studies at the cross-national level (Blakely et al., 2003; Cut- 


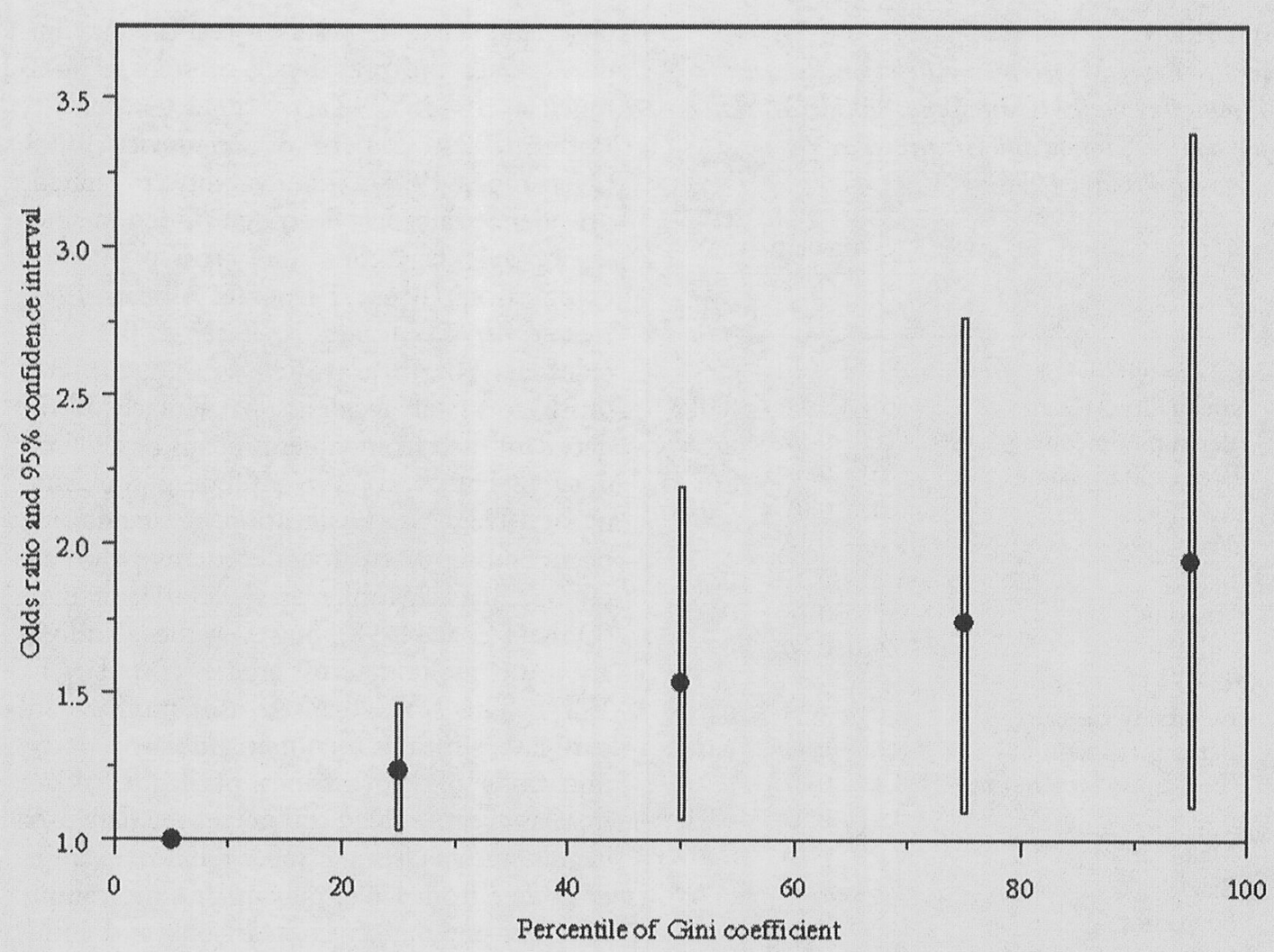

Figure 2. Predicted odds of death by suicide by the Gini coefficients observed across community districts in this study using the midpoint of the most egalitarian decile as the referent.

right \& Fernquist, 2000; Fernquist, 2003; Fernquist \& Cutright, 1998; Gunnell et al., 2003; Kowalski et al., 1987; Lynch et al., 1998; Lester, 1987; Unnithan, 1994; Young et al., 1996). Despite these rationales, and the precedence for the use of community districts in other epidemiologic studies, we may have chosen an inappropriate level of aggregation. Aggregating data at the neighborhood level rather than the census tract or zip code level may mask small area characteristics that mediate the observed association. Nonetheless, our work analyzes data at a lower level of aggregation than previous studies of income inequality and suicide.

We used accidental deaths as controls in this multilevel case-control study. Although accident controls have been used successfully in other multilevel analyses (Galea et al., 2003), our results must be interpreted with due consideration to the choice of con- trol group. It is possible that the relative increase of suicide risk in high income inequality neighborhoods reflects a lower risk of accidents in these same neighborhoods. If income inequality is also associated with an increased rate of non-overdose fatal accidents (Dedeoglu, 1990; Palazzo, Guest, \& Almgren, 2003; Valkonen et al., 2000), then using non-overdose fatal accident decedents as our controls would decrease the probability of disproving the null hypothesis and would likely underestimate the strength of the association between income inequality and suicide. The consistency of the empiric findings documented here with the hypothesized relations based on conceptual understanding of the potential role of income inequality suggest that our selection of controls adequately represented the relevant population casebase. The causes of fatal accidents in decedents over the age of 65 are predominately 
short falls; a substantial proportion of these are likely due to central nervous system deficits, underlying dementia, and intra-cerebral hemorrhages. As such, we restricted our analysis to decedents aged 15 to 64 . This restriction may obscure a relation between income distribution and suicide in older patients. Excluded cases and controls differed slightly by age but were otherwise demographically similar. A greater percentage of controls were excluded than cases. These differences are only likely to be significant if there was bias in address ascertainment between cases and controls. Since our inclusion criteria required a known address of residence within NYC, the findings of this study cannot be extrapolated to comment on the effect of income inequality and suicide on homeless or transient populations in New York. The relation of income inequality to suicide in transient or homeless populations is a potentially important question left unanswered by this study.

Our analyses are limited by the temporality of our data. Our measured outcomes occurred in 1996. We used 1990 census data. These conditions implicitly assume limited

\section{REFERENCES}

Aihara, H. \& Iki, M. (2003). An ecological study of the relations between the recent high suicide rates and economic and demographic factors in Japan. Fournal of Epidemiology, 13, 56-61.

Akers, R. L., \& Sellerrs, C. S. (2004). Criminological theories introduction, evaluation, and application (4th ed.). Los Angeles, CA: Roxbury.

Berkman, L. F., Glass, T., Brissette, I., \& Seeman, T. E. (2000). From social integration to health: Durkheim in the new millennium. Social Science of Medicine, 51, 843-857.

Blakely, 'I'., Atikinson, J., \& O'Dea, D. (2003). No association of income inequality with adult mortality within New Zealand: A multi-level study of 1.4 million 25-64 year olds. Fournal of Epidemiology and Community Health, 57, 279-284.

Borges, G., Anthony, J. C., \& Garrison, C. Z. (1995). Methodological issues relevant to epidemiologic investigations of suicidal behaviors of adolescents. Epidemiology Revicw, 17, 228-239.

Borrell, C., Rodriguez, M., Ferrando, J., Brugal, M. T., Pasarin, M. I., Martinez, V., et AL. (2002). Role of individual and contextual ef- migration and a 6 year time-lag between income inequality and risk of suicide. It is plausible that a longer or shorter period between exposure and outcome would alter the observed association between suicide and income inequality (Geronimus \& Bound, 1998). While rolling averages may stabilize year-toyear fluctuations in relatively uncommon events, like suicide, they also introduce additional assumptions regarding the temporal relation between exposure and outcome. Different time lags merit closer attention and may help clarify the relation of income inequality to suicide (Geronimus \& Bound, 1998).

Finally we were limited in the individual-level variables that could be controlled for by the variables that are available in the dataset used here. Further analyses might consider the role of potential individual-level mediators such as foreign born status.

With caveats acknowledged, we demonstrated an association between neighborhood-level income inequality and suicide in younger decedents in New York City. Future studies should systematically test the pathways through which income inequality may affect suicide mortality.

fects in injury mortality: New evidence from small area analysis. Injury Prevention, 8, 297-302.

BRAUCHT, G. N. (1979). Interactional analysis of suicidal behavior. Fournal of Consulting and Clinical Psycbology, 47, 653-669.

Brent, D. A., Perper, J. A., \& Allman, C. J. (1987). Alcohol, firearms, and suicide among youth-temporal trends in Allegheny County, Pennsylvania, 1960 to 1983. Fournal of the American Medical Association, 257, 3369-3372.

Bureau of till: Crensus. (1999). Census summary tape, file 3A (STF 3A). U.S. Department of Commerce, Washington, DC. Retrieved from http://www.census.gov/ftp/pub/population/www. estimates/co_crh.html

Carr, J. R., Hoge, C. W., Gardner, J., \& Potter, R. (2004). Suicide surveillance in the U.S. Military-reporting and classification biases in rate calculations. Suicide and Life-Threatening Behavior, 34, 233-241.

Cullen, M., \& Whiteford, H. (2001). The interrelations of social capital with bealth and 
mental bealth. Canberra, Australia: Common Wealth of Australia.

Cutright, P., \& Fernquist, R. M. (2000). Effects of societal intergation, period, region, and culture of suicide on male age-specific suicide rates: 20 developed countries, 1955-1989. Social Science Research, 29, 148-172.

Deaton, A. (2003). Health, inequality, and economic development. Fournal of Economic Literature, 41, 113-158.

Dedeoglu, N. (1990). Health and social inequalities in Turkey. Social Science or Medicine, 31, 387-392.

Dooley, D., Catalano, R., Rook, K., \& Serxner, S. (1989). Economic stress and suicide: Multilevel analyses. Part 2: Cross-level analyses of economic stress and suicidal ideation. Suicide and Life-Threatening Behavior, 19, 337-351.

Fernquist, R. M. (2003). Perceived income inequality and suicide rates in Central/Eastern European countries and Western countries, 1990-1993. Death Studies, 27, 63-80.

Fernquist, R. M., \& Cutright, P. (1998). Societal integration and age-standardized suicide rates in 21 developed countries, 1955-1989. Social Science Research, 27, 109-127.

Finkel, M. L., \& Eukrn, E. (2001). Trends in birth rates: New York City 1970-1995. Journal of Community Health, 26, 407-421.

Galea, S., Ahern, J., Vlahov, D., Coffin, P. O., Fuller, C., Leon, A. C., et AL. (2003). Income distribution and risk of fatal drug overdose in New York City neighborhoods. Drug and Alcobol Dependence, 70, 139-148.

Geronimus, A. T., \& Bound, J. (1998). Use of census-based aggregate variables to proxy for socioeconomic group: Evidence from national samples. American Journal of Epidemiology, 148, 475-486.

Gunnell, D., Middleton, N., Whitley, E., Dorling, D., \& Frankel, S. (2003). Why are suicide rates rising in young men but falling in the elderly? A time-series analysis of trends in England and Wales 1950-1998. Social Science and Medicine, 57, 595-611.

Judge, K., \& Paterson, I. (2001). Poverty, income inequality and health. 01/29. Treasury Working Paper. Retrieved from http://www.treasury. govt.nz/workingpapers/2001/01-29.asp

Kawachi, I. \& Berkman, L. F. (2001). Social ties and mental health. Fournal of Urban Healtb: Bulletin of the New York Academy of Medicine, 78, 458-467.

Kawachi, I., \& Kennedy, B. P. (1997). The relationship of income inequality to mortality: Does the choice of indicator matter? Social Science and Medicine, 45, 1121-1127.

Kawachi, I., Kennedy, B. P., \& Wilkinson, R. G. (1999). Crime: Social disorganization and relative deprivation. Social Science and Medicine, 48, 719-731.

Kennedy, B. P., Kawachi, I., ProthrowStrth, D., Lochner, K., \& Gupta, V. (1998). Social capital, income inequality, and firearm violent crime. Social Science and Medicine, 47, 7-17.

Kowalski, G. S., Faupel, C. E., \& Starr, P. D. (1987). Urbanism and suicide-A study of American counties. Social Forces, 66, 85-101.

Lester, D. (1987). Relation of income inequality to suicide and homicide rates. Fournal of Social Psychology, 127, 101-102.

Lester, D. (1991). Social correlates of youth suicide rates in the United States. Adolescence, 26, 55-58.

Lester, D. (1992). Miscounting suicides. Acta Psycbiatrica Scandinavica, 85, 15-16.

Lowenkamp, C. T., Cullen, F. T., \& Pratt, T. C. (2003). Replicating Sampson and Groves's Test of Social Disorganization Theory: Revisiting a criminological classic. Journal of Researcb in Crime and Delinquency, 40, 351-373.

Lynch, J. W., Kaplan, G. A., Pamuk, E. R., Cohen, R. D., Heck, K. E., Balfour, J. L., et al. (1998). Income inequality and mortality in metropolitan areas of the United States. American Fournal of Public Health, 88, 1074-1080.

Mann, J. J., Huang, Y. Y., Underwood, M. D., Kassir, S. A., Oppenheim, S., Kelly, T. M., ET AL. (2000). A serotonin transporter gene promoter polymorphism (5-HTTLPR) and prefrontal cortical binding in major depression and suicide. Archives of General Psychiatry, 57, 729-738.

Marzuk, P. M., Tardiff, K., Leon, A. C., Hirsch, C. S., Stajic, M., Portera, L., et al. (1997). Poverty and fatal accidental drug overdoses of cocaine and opiates in New York City: An ecological study. American Fournal of Drug and Alcobol Abuse, 23, 221-228.

Messner, S. F. \& Tardiff, K. (1986). Economic inequality and levels of homicide: An analysis of urban neighborhoods. Criminology, 24, $297-$ 317.

Mohler, B., \& Earls, F. (2001). Trends in adolescent suicide: Misclassification bias? American Fournal of Public Health, 91, 150-153.

Neeleman, J. (2002). Beyond risk theory: Suicidal behavior in its social and epidemiological context. Crisis, 23, 114-120.

Neeleman, J., Wilson-Jones, C., \& WessELy, S. (2001). Ethnic density and deliberate self harm: A small area study in south east London. Fournal of Epidemiology and Community Health, 55, $85-90$.

New York City Department of City Planning. (2003). District profiles. Retrieved from http://www.ci.nyc.ny.us/html/dcp/html/lucds/ cdstart.html

Ohrerg, A. \& Lonnqvist, J. (1998). Sui- 
cides hidden among undetermined deaths. Acta Psycbiatrica Scandinavica, 98, 214-218.

Ovenstone, I. (1973). Psychiatric approach to diagnosis of suicide and its effect upon Edinburgh statistics. British Fournal of Psychiatry, 123, 15-21.

Palazzo, L., Guest, A., \& Almgren, G. (2003). Economic distress and cause-of-death patterns for Black and non-Black men in Chicago: Reconsidering the relevance of classic epidemiological transition theory. Social Biology, 50, 102.

Sampson, R. J., \& Groves, W. B. (1989). Community structure and crime: Testing socialdisorganization theory. The American 7ournal of Sociology, 94, 774.

Sampson, R. J., Raudenbush, S. W., \& Earls, F. (1997). Neighborhoods and violent crime: A multilevel study of collective efficacy. Science, 277, 918-924.

Spicer, R. S., \& Miller, T. R. (2000). Suicide acts in 8 states: Incidence and case fatality rates by demographics and method. American 7ournal of Public Health, 90, 1885-1891.

Stanley, M., \& Mann, J. J. (1983). Increased serotonin-2 binding sites in frontal cortex of suicide victims. Lancet, 1, 214-216.

Stanley, M., Virgilio, J., \& Gershon, S (1982). Tritiated imipramine binding sites are decreased in the frontal cortex of suicides. Science, 216, 1337-1339.

UNNITHAN, N. P. (1994). The currents of lethal violence: An integrated model of suicide and bomicide. Albany: State University of New York Press.
Valkonen, T., Martikainen, P., Jalovaara, M., Koskinen, S., Martelin, T., \& Makela, P. (2000). Changes in socioeconomic inequalities in mortality during an economic boom and recession among middle-aged men and women in Finland. The European Fournal of Public Health, 10, 274280.

Walime, D., Schill, M. H., \& Daniels, G. (2003). State of New York City's bousing and neighborboods 2002. New York: Furman Center for Real Estate and Urban Policy, School of Law and Robert F. Wagner Graduate School of Public Service, New York University.

Whitley, E., Gunnell, D., Dorling, D., \& SMITH, G. D. (1999). Ecological study of social fragmentation, poverty, and suicide. British Medical 7ournal, 319, 1034-1037.

Wilson, M., \& Daly, M. (1997). Life expectancy, economic inequality, homicide, and reproductive timing in Chicago neighbourhoods. British Medical Fournal, 314, 1271-1274.

Young, T. J., \& French, L. A. (1996). Suicide and homicide rates among U.S. Indian Health Service Areas: The income inequality hypothesis. Social Behavior and Personality, 363-366.

Zeger, S. L., \& LiANG, K. Y. (1986). Longitudinal data analysis for discrete and continuous outcomes. Biometrics, 42, 121-130.

Manuscript Received: May 12, 2004 Revision Accepted: December 20, 2004 